\title{
EL CRISTIANISMO: VIGENCIA DEL PENSAMIENTO DE COMTE, WEBER Y MARX
}

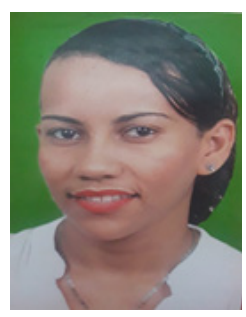

\author{
Jessica Tatiana Guerra Olascoaga ${ }^{1}$ \\ Secretaría de Educación, Montería, Colombia \\ yessygo7@gmail.com
}

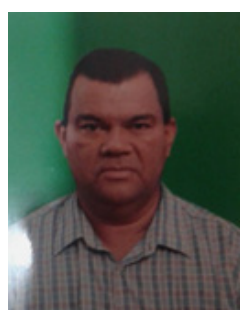

Javier Arturo Gorrostola Nadad ${ }^{2}$

Secretaría de Educación, Montería, Colombia

javiergo20101@hotmail.com

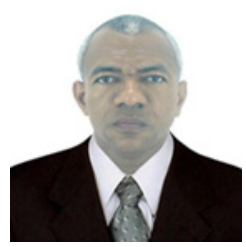

\section{Richar Norman Gómez ${ }^{3}$ \\ Secretaría de Educación, Montería, Colombia rinogo72@hotmail.com}

Fecha de recepción: 01/05/2019

Fecha de revisión: 15/05/2019

Fecha de aceptación: 23/09/2019

\section{RESUMEN}

El aporte que los autores clásicos Augusto Comte, Max Weber y Carlos Marx, han hecho a las Ciencias Sociales desde diferentes ámbitos ha sido muy significativo, éstos se materializan en la fundación de corrientes como el positivismo, la sociología y el marxismo. El presente artículo no solo pretende analizar cómo estos autores a través del cristianismo han mantenido vigente su pensamiento sino comprender la vigencia del pensamiento clásico por medio de apreciaciones a esta religión.

Con algunas producciones intelectuales, éstos clásicos de las ciencias sociales han establecido contrastes y similitudes respecto a la utilidad del cristianismo en la historia, desde la filosofía positivista de Comte, lo visibilizó con la llamada ley de la evolución intelectual de la humanidad o

\footnotetext{
${ }^{1}$ Licenciada en educación básica con énfasis en ciencias sociales y maestrante en Ciencias sociales, Colombia, docente tutora del programa para la excelencia docente del MEN, Todos a Aprender, en el municipio de Montería, Córdoba - Colombia. Miembro de la Red Colombiana de grupos de investigación en didáctica de las ciencias sociales de la Universidad Córdoba.
} 
ley de los tres estadios. Weber, hace una interpretación del cristianismo a través de su obra cumbre la Ética Protestante y el Espíritu del capitalismo; y Marx, hace algunas consideraciones partiendo del origen del cristianismo y luego analiza la relación con el marxismo, en este punto se pudo evidenciar que en América Latina existen puntos de convergencia.

Respecto a las conclusiones, la más evidente enfatiza la relación entre cristianismo y marxismo, la cual más que de esencia filosófica es de conveniencia ideológica, y política.

Palabras clave: Cristianismo, Pensamiento Comtiano, Weberiano, Marxista.

\title{
CHRISTIANITY: VALIDITY OF THE THOUGHT OF COMTE, WEBER AND MARX
}

\begin{abstract}
The contribution that the classic authors Augusto Comte, Max Weber and Carlos Marx have made to the Social Sciences from different areas has been very significant, these materialize in the foundation of currents such as positivism, sociology and Marxism. The present article not only tries to analyze how these authors through Christianity have maintained their thought but to understand the validity of the classic thought by means of appreciations to this religion.
\end{abstract}

With some intellectual productions, these classics of the social sciences have established contrasts and similarities with respect to the usefulness of Christianity in history, from the positivist philosophy of Comte, he visualized it with the so-called law of the intellectual evolution of humanity or the law of the three stadiums. Weber, makes an interpretation of Christianity through his masterpiece the Protestant Ethic and the Spirit of capitalism; and Marx, makes some considerations starting from the origin of Christianity and then analyzes the relationship with Marxism, at this point it was possible to show that in Latin America there are points of convergence.

Regarding the conclusions, the most evident one emphasizes the relationship between Christianity and Marxism, which is more of ideological and political convenience than of philosophical essence.

Key words: Christianity, Comtian, Weberian, Marxist Thought

\section{INTRODUCCIÓN}

Para comprender la vigencia del pensamiento clásico de las ciencias sociales. En Marx, Comte y Weber a la luz del mundo contemporáneo. Se hace imprescindible abordarlos desde el 
cristianismo, ya que ha sido la religión que más ha impactado el desarrollo de la historia de la humanidad desde la Europa antigua, especialmente en el medioevo. Esta ha estado unida al desarrollo social, político, económico y cultural no solamente del llamado antiguo continente, sino del nuevo mundo, con la llegada de los europeos a América, al difundirse inicialmente como un proceso de adoctrinamiento hacia las poblaciones indígenas, y luego con el fortalecimiento de las instituciones coloniales de manera progresiva.

Este trabajo pretende abordar los contrastes y las similitudes de la vigencia del pensamiento de los clásicos de las ciencias sociales tales como Augusto Comte, Max Weber y Karl Marx en torno al cristianismo haciendo una retrospectiva de cuál ha sido su impacto en el mundo contemporáneo.

Para emprender dicha temática es necesario hacer un análisis de las condiciones históricas bajo las cuales surge la religión cristiana, que como bien lo plantea Engels, F en su obra "La historia del cristianismo originario (1894):

Tiene un notable parecido con la del moderno movimiento obrero. Al igual que este último, el cristianismo fue en sus orígenes un movimiento de un pueblo oprimido: apareció por primera vez como la religión de esclavos y libertos, pobres privados de todo tipo de derechos, de pueblos subyugados o dispersos por Roma. Tanto el cristianismo como el socialismo obrero predican una futura salvación de la esclavitud y [de la] pobreza. El cristianismo ubica esta salvación en una vida en el más allá, después de la muerte, en el cielo; el socialismo lo ubica en este mundo. Ambos son perseguidos y acosados, sus adherentes son aborrecidos y objeto de leyes de exclusión... (p 127).

Esta es la forma, como muchos autores en las diferentes épocas de la historia concibe la existencia y consolidación de una creencia que ha controvertido y la vez revolucionado el pensamiento de aquellos que profesan la fe cristiana. Por ende, se hace necesario, conocer desde el punto de vista de la filosofía positivista la vigencia de este pensamiento en torno al cristianismo.

\section{AUGUSTO COMTE: FILOSOFÍA POSITIVISTA}

En una incomparable exposición al denso y claro pensamiento de Augusto Comte, se encierra vigorosamente los momentos fundamentales de sus concepciones y los agrupa en el sistema de filosofía positiva, que es la peregrina suerte del positivismo, para convertirlo en casi-religión, el hecho que llegue a nosotros de forma jerarquizada e hieratizada (solemne, rígida), es decir, la sistematización de la teoría positiva como el principio de la cientificidad, determinante, y radical.

La ley de la evolución intelectual de la humanidad o ley de los tres estadios, sostiene que: 
Todas nuestras especulaciones, cualesquiera, están sujetas inevitablemente, sea en el individuo, sea en la especie, a pasar sucesivamente por tres estados teóricos distintos, que las denominaciones habituales de teológico, metafísico y positivo podrán calificar aquí suficientemente, para aquellos, al menos, que hayan comprendido bien su verdadero sentido general. Aunque, desde luego, indispensable en todos aspectos, el primer estado debe considerarse siempre, desde ahora, como provisional y preparatorio; el segundo, que no constituye en realidad más que una modificación disolvente de aquél, no supone nunca más que un simple destino transitorio, a fin de conducir gradualmente al tercero; en éste, el único plenamente normal, es en el que consiste, en todos los géneros, el régimen definitivo de la razón humana. (Comte, A 1844)

Esencialmente, el estadio teológico corresponde a la condición humana que un gran número experimenta de manera individual, supeditada a la creencia de un ser supremo, donde predomina la magia, la hechicería y lo sobrenatural donde existe un dios creador y preservador que, según la cultura y el espacio geográfico, se diferencia por el culto a los mismos, ya que pueden ser mono y politeísta, esto es, lo que el autor cataloga como un estado ficticio, fetichista y especulativo.

En el estadio metafísico o abstracto, los conocimientos son absolutos, hay acciones prolongadas en las concepciones ontológicas y las abstracciones son personificadas, como es el caso de las estatuas que a su vez representan las creencias. Y finalmente,

En el estadio positivo o real, se emplea el método científico, y se caracteriza por ser superior a los dos anteriores, la imaginación subordina la observación, por lo que la razón humana, viene a ser la esencia misma del estadio, su frase insigne es ver para que creer y no se mide al hombre sino al colectivo, mediante el reconocimiento de la realidad social mediante el método filosófico, la moral es independiente, ya que las actuaciones van de acuerdo a sus preceptos, por ser de esencia emancipadora, explicativa y racional, desarrollando la capacidad para discernir y un credo laico al capitalismo, trayendo gran oxigenación e imposición a este sistema económico.

Con el problema del activismo, se sistematizaron creencias y con la sistematización y publicación de la realidad, tomó gran auge las ciencias sociales, por lo que hoy día ésta y el positivismo no pueden estar separadas, debido a que su vigencia y fundamentación le dan mayor rigor a su objeto de estudio y método.

A manera de reflexión, el cristianismo a través del protestantismo busca justificar: "La expectativa de ganancia por medio del aprovechamiento de posibilidades de intercambio; es decir: 
sobre posibilidades lucrativas (formalmente) pacificas", Weber (2009) en las ideas calvinistas justifican a partir del momento en que nacemos la teoría de la predestinación, o sea, se ésta predestinado a condenarse o salvarse más allá de lo que se haga o se deje de hacer en la vida, esto conduce a que la persona verifique si es o no un elegido, dependiendo de una soberana decisión divina, donde las buenas obras no sirven para nada. Las peores acciones son un lujo que cualquiera se puede dar, si se es un condenado qué más da, las posibilidades de pasarla lo mejor posible al precio que sea, pero si se tiene éxitos en los proyectos y se obtiene una alta posición social, muy probablemente sea un elegido porque de no ser así dios no premiaría con éxito, de un modo u otro el éxito lo justifica todo.

Seguidamente, $\mathrm{y}$ en la búsqueda por explicar la fundamentación de la corriente anti positivista que marca el origen del espíritu del capitalismo en occidente y aquellas ideas que influenciaron la sociología de la religión se tiene a:

\section{MAX WEBER: SOCIOLOGÍA DE LA RELIGIÓN}

El economista, político y sociólogo alemán, fundador del estudio moderno anti positivista, de la sociología y la administración pública Max Weber, a través de su obra cumbre la Ética Protestante y el Espíritu del capitalismo, responde a la pregunta del problema teórico del pensamiento weberiano, el cual radica en explicar ¿cómo surgió el capitalismo occidental y la presentación de la tesis de que la ética y las ideas puritanas influenciaron el desarrollo del capitalismo?

La devoción religiosa es usualmente acompañada del rechazo de los asuntos mundanos, incluyendo la búsqueda de una mejor posición económica, aceptando que la espiritualidad no está lejos de la riqueza y todo ascetismo esta religado a complejos y prácticas tradicionales de aquellos que buscan mitigar el avance en las masas. Posteriormente, define al "espíritu del capitalismo" como las ideas y hábitos que favorecen la búsqueda racional de ganancias económicas. Weber señala que tal espíritu no existe, solamente en la cultura occidental, cuando se considera como una actitud presente en los individuos ya que también hay que tomar en cuenta que estos individuos no podrían, por sí solos, establecer un nuevo orden económico como el capitalismo. Entre las tendencias identificadas por Weber está la ambición de ganancias con un mínimo esfuerzo; la idea de que el trabajo es una maldición y una carga que debe evitarse, especialmente cuando las ganancias de éste exceden lo que es necesario para una vida modesta. Pero "Para que una forma de vida bien adaptada a las peculiaridades del capitalismo" - escribió Weber — "pueda superar a otras, debe originarse en algún lugar, y no solo en individuos aislados, sino como una forma de vida común a grupos enteros de personas”.

En consecuencia, Weber propone a través de la sociología de la religión, que ésta fue uno de los 
aspectos más influyentes en las diferencias en el desarrollo de la cultura occidental y oriental y que darle respuesta al interrogante: ¿Qué serie de circunstancias ha determinado que sólo en Occidente hayan surgido ciertos hechos culturales sorprendentes, que - al menos así nos place imaginarlo - estuvieron orientados hacia un desarrollo de validez y alcances universales? es el argumento perfecto para iniciar el ensayo a la crítica a la concepción materialista de la historia de Karl Marx, donde "no solo los intereses económicos determinan el devenir histórico, sino que el movimiento de clases y las grandes corrientes sociales influyen de forma principal en aquellos factores de carácter psicológico y religioso de la sociedad”. Weber (2009). Este último es considerado por el marxismo como el "opio del pueblo, que es la quinta esencia de la concepción marxista del fenómeno religioso por la mayoría de sus partidarios y oponentes.” Lowy (2006)

He aquí el contraste de la vigencia del pensamiento Weberiano y el marxista.

\section{KARL MARX Y EL CRISTIANISMO}

Comúnmente se podría considerar que en el mundo de hoy entre el marxismo y el cristianismo no hay posibilidad de empatía, no hay lugar para la concertación, ya que el marxismo, al tener como base filosófica al materialismo, por naturaleza es anticristiano. Sin embargo, no resultaría inoportuno hacer el intento por buscar elementos de convergencia que históricamente han podido identificar algunas alianzas bien sea por conveniencias o circunstancia bajo las cuales estas doctrinas o ideologías han podido mantenerse en un mundo lleno de tantas complejidades y escepticismos:

Al respecto, en el texto: cristianismo y Marxismo: ¿Un diálogo de otro tiempo? de Álvarez, D. (2009), plantea:

Ya pasó de moda ser marxista", dirán algunos; y menos aún, intentar ser a su vez cristiano, algo que, por lo demás, se ve hoy como esencialmente contradictorio. Es explicable que muchos quieran entender la relación entre cristianismo y marxismo como un consuelo mutuo. (p. 161)

Para el marxismo, el cristianismo surge bajo unas condiciones sociales que expresan una evidente desigualdad entre clases y sectores sociales que anhelaban una liberación, por ello la figura de Jesús de Nazaret fundador del cristianismo hace eco en ese pueblo de Israel oprimido por el gran imperio romano.

En ello vale la pena mirar las condiciones políticas y económicas bajo las cuales surge el cristianismo:

Según, Alvar, J et al, en su libro “Cristianismo Primitivo y Religiones Mistéricas”, en el capítulo II: "El mundo en que nació el cristianismo” J.M Blázquez sustenta que:

Roma respetó las costumbres religiosas judías por conveniencia política. Por tal razón 
no se instalaron en Jerusalén estatuas ni estandartes. Sin embargo, otros aspectos de la política de Roma con los judíos provocaron el odio hacia Roma, como el nombramiento por los gobernadores romanos del sumo sacerdote, y el cobro de duras contribuciones. La situación se agravó por la dureza y poca habilidad de ciertos gobernadores romanos, como Pilato al introducir en Jerusalén los estandartes del ejército, y al sustraer cierta cantidad del tesoro del templo para costear obras de abastecimiento de agua para la ciudad. Por su parte, los judíos ricos pertenecían a la familia de Herodes y a la oligarquía sacerdotal, que era saducea. Gran parte de la masa popular era pobre, según el testimonio de los evangelios. Los artesanos también desempeñaban un papel importante en la economía palestina. (pp. 48-49)

De acuerdo con el marxismo las instituciones políticas, religiosa, legales e ideólogas están condicionadas por la base económica de la sociedad.

Por otra parte, en el texto: cristianismo y marxismo: ¿Un diálogo de otro tiempo? de Álvarez, D. (2009), describe:

El encuentro, colaboración e historia de movimientos de base tanto cristiana como marxista. El contexto es la España de la dictadura franquista y la Transición, exponiendo cómo en el camino de la gestación a la democracia se buscaron medios que asentasen una alianza entre unos sistemas de pensamientos no tan opuestos entre sí como en principio podría parecer. Con una minoría de comunistas y socialistas que se podrían considerar dentro de una órbita cristiana. (p 161)

No obstante, a nivel internacional, la Segunda Guerra Mundial tuvo una repercusión decisiva en el desarrollo de la relación:

Muchos cristianos lucharon hombro a hombro junto a los comunistas en contra del nazismo, o tuvieron que soportar también juntos las penalidades de los campos de concentración. La realidad de estos hechos, unido a la vida compartida en la resistencia contra la ocupación nazi les hace descubrir a los unos y a los otros sus verdaderos rostros, no las respectivas imágenes que se habían fabricado. (Álvarez, D. 2009-162)

En el texto, el autor resalta como en un conflicto de gran envergadura como la segunda guerra mundial, los cristianos lucharon junto a los comunistas contra sistemas de opresión como el nazismo que no solamente limitaba las libertades individuales, sino que se caracterizó por actos de genocidios contra los judíos. Algo que en la historia humana quedó impregnado como la irracionalidad perversa y desenfrenada, de una ideología que conduce a la barbarie, como si la 
experiencia de las guerras del pasado y los conflictos atroces pasaran desapercibidos.

Por ende, Álvarez, D. (2009), Afirma que:

La multiplicación de debates, confrontaciones, semanas de estudios, entre católicos y marxistas es notable en los años sesenta: semanas del pensamiento marxista en París y en Lyon (1964) con la presencia de cristianos, y con la de marxistas en la semana de los intelectuales católicos de París (1965); encuentros entre católicos y marxistas italianos en Florencia (1964). (p 162).

En otro contexto, como el latinoamericano la relación entre cristianismo y marxismo, es algo que puede parecer inverosímil pero que resultaría interesante analizar.

En el libro "cristianismo y Revolución. Los orígenes intelectuales de la guerrilla en la Argentina” de Morello, G y Barón Del Pópolo, G (2010) plantea:

Es muy importante marcar una diferencia clara entre "reformismo conciliar" y "cristianismo revolucionario". Por más que el segundo recurrió repetidamente al primero en busca de un "aval", de una legitimación frente al "pueblo cristiano", y de que de hecho el primero también sirvió de disparador de procesos cristianos de radicalización, la diferencia es esencial, mientras el reformismo católico busca una reconciliación con el presente, el cristianismo revolucionario tiene un compromiso con el futuro.

De acuerdo con el autor, existe una alianza entre marxismo y cristianismo en el cual el cristianismo llamado revolucionario ve el mundo bajo una óptica diferente ha como la observa el catolicismo tradicional, porque:

La teología de la liberación teóricamente y el cristianismo revolucionario en la praxis, efectúan en el pensamiento religioso una inversión paralela a la que el marxismo realiza con la filosofía. Ponen con los pies en la tierra lo que estaba de cabeza. Vuelven al hombre concreto, necesitante y deseante, del primer cristianismo y de la tradición semítica. Una inversión paralela que incluso es una y la misma, ya que la filosofía idealista es el resultado directo del "occidente cristiano"2.

\footnotetext{
${ }^{2}$ Esta interpretación nos viene de la lectura de Enrique Dussel (particularmente "El Dualismo en la Antropología de la Cristiandad"; Editorial Guadalupe; Buenos Aires, 1974; "El Humanismo Helénico"; EUDEBA; Buenos Aires, 1974 y "El Humanismo Semita"; EUDEBA; Buenos Aires, 1969) y Franz Hinkelammert ("Las Armas Ideológicas de la Muerte"; Segunda edición revisada y ampliada; Editorial Departamento Ecuménico de Investigaciones (D.E.I.); San José y "La Fe de Abraham y el Edipo Occidental”; Editorial Departamento Ecuménico de Investigaciones (D.E.I.); San José, 200+0).
} 
Es en este sentido, que se puede entender al cristianismo revolucionario, que está muchísimo más allá que el pensamiento del tradicionalismo católico porque incluso ha superado, dialécticamente, al reformismo católico. Por ello, se puede entender la posición adecuadamente resaltada por Morello de la búsqueda del lugar de los cristianos en una "revolución laica" en contra de una Cristiandad de Izquierda (si tal cosa fuera posible siquiera conceptualmente). El compromiso de los cristianos revolucionarios es, como dijimos, con el futuro, y con un futuro plenamente "moderno". A pesar de contener elementos románticos y místicos (¿qué pensamiento revolucionario no los tiene?) el cristianismo revolucionario se apoya en la razón y el humanismo para ir en busca de la última utopía moderna, el socialismo, en contra de la irracionalidad capitalista. Morello (2010)

Con este respecto, la llamada teología de la liberación, invita a la preferencia por los pobres y una liberación por parte de los cristianos de los aspectos económicos, especialmente; y el cristianismo revolucionario, toman como fundamento el escenario donde tuvo lugar el cristianismo primitivo, donde los oprimidos y empobrecidos bajo el dominio de la Roma imperial, sienten la necesidad y el anhelo de liberarse. Por lo que el marxismo como ideología del socialismo puede hallar un punto de encuentro, una alianza estratégica que se manifiesta en una lucha contra la irracionalidad capitalista que arrasa sin piedad contra todo individuo que en el sistema este desprovistos de bienes de producción.

Tomando en consideración lo expuesto, se puede establecer que, aunque durante medio siglo el marxismo fue el enemigo quizás más contundente de la fe cristiana, en las últimas décadas se ha dado una transformación en los factores sociales del continente, a través de una profunda modificación de la cultura católica latinoamericana que emana de la integración de sectores de la iglesia con temas fundamentales del marxismo. Esta evolución no solamente va a preocupar a miembros de la iglesia católica sino también a representantes del gobierno en la región y en Norteamérica.

Por tanto, el equipo de expertos al servicio del presidente Bush publica un informe - conocido como Santa Fe II en el que retoma, de manera ligeramente más sofisticada, el mismo esquema:

Se trata ahora de la táctica gramsciana de los marxistas, que descubrieron que el método más prometedor para llegar al poder es "dominando la cultura de la nación, lo que implica un proceso para lograr una fuerte influencia en la religión, en las escuelas, en los medios de comunicación, en las universidades, es en este contexto que se debe entender la teología de la liberación: como una doctrina política disfrazada de creencia religiosa con un significado anti-papal y anti-libre empresa, destinada a debilitar la independencia de la sociedad frente al control estatista. Lowy, M. (1989) 
Así mismo, y teniendo en cuenta las palabras del cardenal Ratzinger -principal adversario de la teología de la liberación- ésta, fundamentada en el análisis marxista, se convirtió en seductora. En ello, existen modelos de esperanza de inspiración marxista que pudieron seducir tan significativos sectores de la Iglesia Católica Apostólica Romana en América Latina³.

Para explicar este fenómeno, se debe tener en cuenta que:

Al estudiar la relación recíproca entre una orden religiosa (la ética protestante) y un ethos económico (el espíritu del capitalismo): afinidad electiva (Wahlverwandtschaft). A partir de ciertas analogías, ciertas afinidades, ciertas correspondencias, dos figuras de la cultura pueden - bajo ciertas circunstancias históricas - entrar en una relación de estiramiento, opción, selección de elecciones mutua. No se trata de un proceso unilateral de influencia, sino de un movimiento dinámico, activo, de interacción dialéctica, conduciendo, en algunos casos, a la simbiosis o incluso fusión de las dos estructuras significativas. Weber (1971)

Citado por Lowy (1989 p, 3); en resumen, existe afinidad entre cristianismo y socialismo, entre otros aspectos por la apreciación de la pobre e inocente víctima de la injusticia y tan inmune a la corrupción reinante; y la liberación de los esclavos y oprimidos como un imperativo moral y como un proceso histórico. Y que es en América Latina donde se producen los procesos de manera más radical a la convergencia entre cristianismo y marxismo dadas algunas condiciones:

a) Un desarrollo acelerado del capitalismo, una urbanización intensa y una industrialización rápida (bajo la égida del capital norteamericano), que profundizan las contradicciones sociales, en la ciudad como en el campo;

b) La revolución cubana (1959-60), primera victoria popular contra el imperialismo en América Latina y primera revolución socialista en el continente dictada por fuerzas marxistas de un nuevo tipo, independientes del comunismo tradicional (de inspiración estalinista). (p 5)

Al analizar las relaciones o alianzas bien sea estratégicas o de afinidad electiva entre el cristianismo y marxismo en América latina, es pertinente tener en cuenta lo que significó la revolución cubana en el continente por ser de carácter socialista; para mirar de qué manera se han establecido esas relaciones, hay que tener en cuenta lo planteado por Alonso, A (2011) en el texto La iglesia católica, la política y la sociedad:

\footnotetext{
${ }^{3}$ Ratzinger, "Les consecuencias Fundamentales d'une option marxiste" (1984), las teologías de la liberación, París, Cerf, 1985, p.122-130. [ Enlaces ] Este texto es más antiguo que el famoso "Instrucción sobre algunos aspectos de la" Teología de la liberación "de la Congregación para la Doctrina de la Fe, dirigida por el propio cardenal Ratzinger.
} 
Con frecuencia, he resaltado que, cuando ocurrió la victoria de la Revolución de 1959, la Iglesia, que no había vivido todavía la renovación que introducía el Concilio Vaticano II, no contaba con una proyección que posibilitara una conexión ajustada con la intensidad del cambio que ocurría en la vida política y económica, y en las coordenadas del pensamiento social.

En tales condiciones, nos aventuramos a decir que el caso cubano representaba para su Iglesia un desafío diferente, más que de restauración, de reconstrucción de nexos con una sociedad que cambió y sigue cambiando, con un curso histórico sustancialmente diferente y, claro, con un Estado radicalmente distinto en la orientación del ejercicio de autoridad, que no responde a los intereses de una estructura de explotación de clases, independientemente de sus virtudes y de las deficiencias que podamos apuntar en la gestión del gobierno.

Mas adelante, el autor afirma que:

Para la mayoría de la población cubana creyente se va a presentar un gran dilema durante la década de los años 60 , que tiene que ver con una contradicción entre catolicismo o revolución dada la asimilación del marxismo bajo el carácter ortodoxo soviético ateísta.

Bajo las condiciones señaladas, se puede inferir el grado de dificultad entre cristianismo y marxismo presente entre estas dos ideologías para llegar a un punto de convergencia. Sin embargo, para la década de 1980 empieza un proceso de "reanimación de la espiritualidad religiosa y la actividad eclesiástica católica”. Alonso, A. (2011), esta reanimación se refiere al número creciente de comunidades religiosas y a la aparición de nuevas expresiones de fe por lo que se puede hablar de una inserción activa de la vida religiosa a la sociedad cubana.

Por su parte, el autor plantea los avances del posicionamiento de la Iglesia católica en la década de 1980, reflejado en el documento final del Encuentro Nacional Eclesial Cubano (Enec), de 1986, lo que había sido un indicativo de la recuperación de la presencia del catolicismo en Cuba. En el mismo tiempo, fue publicado en 1985, Fidel y la religión, producto de 23 horas de entrevistas entre el dominico brasileño Frei Betto con Fidel Castro, en la que el jefe de Estado reconoce que hay elementos discriminatorios en la política del socialismo cubano contra la fe religiosa, más tarde esto se supera y se extiende en consideraciones que anuncian una disposición para el cambio de política. (p 5)

Posteriormente, con la llegada del papa Juan Pablo II a Cuba en 1998, se pone de manifiesto la puesta en marcha de un proceso de franca reanimación espiritual, sin precedentes en la Cuba socialista. 


\section{CONCLUSIONES}

Hablar de los contrastes y similitudes entre el pensamiento de Comte y Weber en torno a la religión, es una tarea de aquellos que busca entender los efectos de una práctica que más de tener malas intenciones ha sido objeto de tergiversaciones. Esto es, una propuesta neo evolucionista, que, si bien lo sustenta Schluchter en la atractiva reconstrucción que ofrece de la sociología de la religión de Weber, hablar expresamente de etapas y avances de un proceso de racionalización que progresa y evoluciona cuyo fundamento es el esquema positivista de la ley de los tres estadios, de lo teocéntrico, a lo metafísico y de ahí a la ciencia desmitificada y desencantada. En efecto, condiciona al mundo a ser un escenario con alto grado de interdisciplinariedad.

Por su parte, en la metodología weberiana referida a la religión, «lo importante no es la doctrina de una religión, sino la forma de conducta ética premiada» (Weber [1906] 1972, 393), no la teoría ética de manuales teológicos, que solo sirven como medio de conocimiento, sino los impulsos prácticos a la acción, (Weber 1997, 330) es decir la conducta práctica de los sujetos, que conduce al bienestar y progreso a nivel colectivo y no solo individual, asunto que recuerda el modo como Marx y Engels fundamentan su concepción materialista de la historia, partiendo de la premisa de la existencia de individuos reales, de su acción y sus condiciones materiales de vida, tanto aquellas que han encontrado ya hechas, como las engendradas por su propia acción (Marx \& Engels [1846] 1985a, 15). Hecho que no conlleve a la lucha de clases sino a la igualdad social.

En cuanto al pensamiento Marxista se halla un punto de encuentro con Weber en lo relacionado con el estudio de una relación reciproca de una orden religiosa, donde existe una afinidad electiva, que Weber plantea en su obra "la Ética Protestante y el espíritu del capitalismo" donde se pone en contexto la relación entre Marxismo e iglesia católica en América Latina.

Esta afinidad, se ve reflejada en el hecho de que, pese al ateísmo marxista, es evidente una relación entre cristianismo y marxismo, la cual más que de esencia filosófica es de conveniencia ideológica, y política. En ello especialmente el catolicismo, considera que se deben hacer cambios en su doctrina, acorde a las exigencias de la sociedad, donde la teología de la liberación cobra mucha fuerza; y el marxismo a través de su ideología socialista reconoce el alto grado de influencia del cristianismo como religión en el mundo, por lo que esta alianza estratégica les ha permitido a ambos mantenerse vigente en el tiempo. 


\section{REFERENCIAS BIBLIOGRÁFICAS}

- Alonso, A. (2011). La iglesia católica, la política y la sociedad. Sao Paulo. Scielo Chile.

- Alvar, J, et al. (1995). Cristianismo primitivo y religiones mistéricas. Madrid. Ediciones Cátedra.

- Álvarez Espinosa, D. F. (2009). Cristianismo y Marxismo: ¿un diálogo de otro tiempo? Historia Actual Online, (18), 161-177.

- Comte, A. (1980). Augusto Comte: Discurso sobre el espíritu positivo. Prólogo Julián Marías. Madrid. Alianza Editorial S.A

- Dussel, E. (1974). El dualismo en la antropología de la cristiandad. Buenos Aires. Guadalupe.

- Engels, F. (1894). Sobre la historia del cristianismo originario. Año II - No 2 - octubre de 2011. Revista Teórica de la LIT-CI

- Lowy, M. (2006). Marxismo y Religión: ¿Opio del pueblo? Buenos Aires. Consejo Latinoamericano de Ciencias Sociales (CLACSO)

- Mejía, C. (2013). Karl Marx y Max Weber: ¿ruptura o continuidad? Cali-Colombia. Consejo Latinoamericano de Ciencias Sociales (CLACSO)

- Villegas, F. G. (2015). Max Weber y la guerra académica de los cien años: Historia de las ciencias sociales en el siglo XX. La polémica en torno a La ética protestante y el espíritu del capitalismo (1905-2012). Fondo de Cultura Económica.

- Weber [1906] 1972, 393). Citado por Villegas, F. G. (2015). Max Weber y la guerra académica de los cien años: Historia de las ciencias sociales en el siglo XX.

- Weber $(1997,330)$. Citado por Villegas, F. G. (2015). Max Weber y la guerra académica de los cien años: Historia de las ciencias sociales en el siglo XX.

- Weber, M. (2009). La ética protestante y el espíritu del capitalismo. Traducción de Denes Martos. Edición Original: 1904/1905. Argentina. www.laeditorialvirtual.com.ar 